\title{
Enfermedades infecciosas de relevancia en la producción caprina, historia, retos y perspectivas
}

\author{
Gabriela Palomares Reséndiz ${ }^{\text {a }}$ \\ Francisco Aguilar Romero ${ }^{a}$ \\ Carlos Flores Pérez ${ }^{b}$ \\ Luis Gómez Núñez ${ }^{\text {a }}$ \\ José Gutiérrez Hernández ${ }^{\text {a }}$ \\ Enrique Herrera López ${ }^{\text {a }}$ \\ Magdalena Limón González ${ }^{\text {b }}$ \\ Francisco Morales Álvarez ${ }^{\mathrm{a}}$ \\ Francisco Pastor López ${ }^{\mathrm{c}}$ \\ Efrén Díaz Aparicio ${ }^{a^{*}}$
}

${ }^{a}$ Instituto Nacional de Investigaciones Forestales Agrícolas y Pecuarias (INIFAP). CENID Salud Animal e Inocuidad. Carretera México -Toluca, colonia Palo Alto, 05110. Ciudad de México. México.

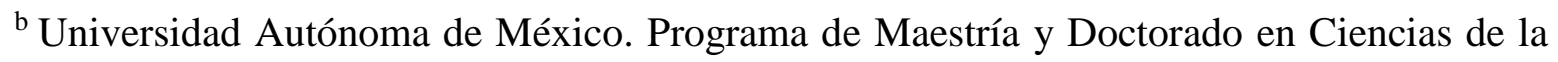
Producción y de la Salud Animal. Ciudad de México, México.

' INIFAP. CE La Laguna, Matamoros, Coahuila, México.

*Autor de correspondencia: efredia@yahoo.com 


\section{Resumen:}

La importancia de las cabras en México radica en que su producción se concentra en zonas áridas y semiáridas del norte y el centro del país, y particularmente en la región de la Mixteca en los estados de Oaxaca, Guerrero y Puebla, donde prevalece la pobreza y donde la especie, es capaz de sobrevivir y producir leche y cabritos. El estudio de las enfermedades de las cabras en México es escaso; el INIFAP se ha caracterizado por nunca haber dejado de lado la investigación en esta especie. En esta revisión, se abordan las principales enfermedades que afectan a las cabras en México y se describen las investigaciones que sobre ellas ha desarrollado el INIFAP. Los problemas de salud que enfrentan la mayoría de los rebaños caprinos en los que se ha realizado investigación, demuestran que algunos trastornos reproductivos son causados por enfermedades como brucelosis, leptospirosis y clamidiasis, todas éstas consideradas endémicas y con potencial zoonótico. Por otra parte, los problemas de tipo respiratorio y digestivo son los principales padecimientos que afectan a los cabritos. En las cabras en etapa productiva del territorio nacional, se ha demostrado una frecuencia elevada de animales con artritis encefalitis, enfermedad causada por la infección de Lentivirus de los pequeños rumiantes, paratuberculosis y linfadenitis caseosa, estas últimas de origen bacteriano; una particularidad de estas tres enfermedades es su característica de cronicidad, lo que hace pensar de manera equívoca al productor que su presencia no tiene mayor impacto dentro de los rebaños. Finalmente, se ha logrado detectar la presencia de la fiebre Q, una enfermedad zoonotica actualmente considerada exótica en México, y que en otros países es frecuentemente asociada con trastornos reproductivos, abortos y ocasionalmente, problemas respiratorios en los animales. En las aportaciones del INIFAP hay que destacar el diagnóstico y el control de la brucelosis, que es la principal zoonosis bacteriana en nuestro país; además de haber contribuido a que enfermedades consideradas exóticas en México, se determine que ya son endémicas, y se cuente con las herramientas para su diagnóstico, siendo un reto para nuestro instituto realizar la transferencia de estas tecnologías a los laboratorios de diagnóstico de nuestro país.

Palabras clave: Caprinos, Enfermedades, Investigación.

Recibido: 14/09/2020

Aceptado: 16/02/2021

\section{La importancia de la caprinocultura en México}

Actualmente México cuenta con una población caprina de $8^{\prime} 791,894^{(1)}$, siendo los estados con la mayor población Zacatecas, San Luis Potosí, Coahuila, Puebla y Oaxaca, los cuales 
tienen una tradición gastronómica donde se utiliza la carne de este rumiante, con platillos como la birria, el cabrito, el mole de caderas y la barbacoa; para tal fin, cuentan con razas especializadas en producción de carne o doble propósito como Boer y Nubia, pero la mayoría de su población sigue siendo de animales criollos o locales, que son descendientes de las razas españolas. En cuanto a la producción de leche, las razas como Saanen, Alpina francesa, Toggenburg y Nubia, se encuentran principalmente en los estados de Coahuila, Guanajuato, Durango, Jalisco y Chihuahua ${ }^{(1)}$; donde se produce queso, cajeta y dulces ${ }^{(2)}$.

Los caprinocultores del Bajío y del norte de México cuentan con mayor nivel de tecnificación en comparación a los del sur, como las regiones Mixtecas y Guerrero, probablemente por su fin zootécnico, ya que la producción de leche es demandada por la industria, siendo varias las empresas que elaboran lácteos y requieren de la materia prima. Los sistemas de producción regionales son heterogéneos, con tecnología tradicional, problemas de sanidad, con escasa organización de los productores y en el trabajo de la cadena de valor ${ }^{(3)}$.

La importancia de las cabras como productoras de alimento y como actividad económica, cobra más relevancia en las zonas áridas y semiáridas, donde prevalece la pobreza. La cabra es capaz de aprovechar la vegetación de las zonas, lo que la convierte en la principal especie ganadera que tiene la capacidad de adaptarse y producir, aún en condiciones desérticas desventajosas $^{(4)}$.

\section{Brucelosis}

El principal agente etiológico de la brucelosis en caprinos es B. melitensis, también es la principal especie del género y se considera como uno de los agentes causales de la brucelosis humana, conocida como Fiebre de Malta ${ }^{(5)}$.

La más importante vía de trasmisión de esta enfermedad es la oral, por la ingesta de alimento o agua contaminados con secreciones vaginales o restos de abortos de animales infectados. Para las brucelas de fenotipo liso, no se acepta que la vía venérea tenga importancia epidemiológica en la transmisión de la enfermedad, sin embargo, B. melitensis es excretada en leche y calostro, de tal modo que la mayoría de las infecciones latentes probablemente se contraen a través del consumo de estos productos ${ }^{(5)}$.

El ganado al infectarse presenta signos clínicos de gran importancia económica, en las hembras sexualmente maduras provoca reducción de la fertilidad, aborto y disminución en la producción de leche; en los machos coloniza el aparato reproductivo ocasionando orquitis y epididimitis; también se han reportado casos de $\operatorname{artritis}^{(6)}$.

La prueba de tarjeta con antígeno de B. abortus a una concentración del 3\%, es la más utilizada para el diagnóstico serológico de brucelosis en caprinos; esta prueba tiene una 
sensibilidad cercana al $100 \%$, además es sencilla, económica y práctica. Sin embargo, en caso de cabras vacunadas con Rev 1 a cualquier dosis, la campaña establece que no debe realizarse la prueba de tarjeta, hasta después de ocho meses post vacunación, ya que antes, esta prueba no es capaz de diferenciar entre anticuerpos vacunales y de infección. Por lo cual se deben utilizar técnicas como la inmunodifusión radial (IDR) con hapteno nativo, que permite diferenciar a los animales vacunados de los infectados ${ }^{(7)}$.

En México. La brucelosis es la principal zoonosis bacteriana; el control se apoya en el diagnóstico, la identificación de los animales infectados, en la eliminación de los mismos, y sobre todo en la vacunación. Las poblaciones humanas vulnerables incluyen no solo a los caprinocultores, especialmente en comunidades marginadas de cría de cabras, veterinarios y trabajadores de mataderos, pero también personal de laboratorio y consumidores de productos lácteos no pasteurizados ${ }^{(5)}$.

\section{Aportaciones de las investigaciones realizadas en el INIFAP}

A finales de los años noventa, se retomó la Campaña Nacional contra la Brucelosis Animal, encontrando en ese momento ante una falta de información científica referente a la protección que confería la vacuna Rev 1 a las cabras, que era y sigue siendo usada a nivel mundial como la única opción para prevenir la brucelosis en los pequeños rumiantes. En el INIFAP se realizaron evaluaciones de la vacuna, determinando la protección conferida frente al desafío experimental. Se concluyó, que el uso de dosis reducida de Rev 1 protegió a las cabras vacunadas en áreas endémicas durante al menos cinco años después de la inmunización. Estos resultados son los únicos a nivel mundial, donde se aporta el respaldo científico a que la vacuna Rev 1 protege a la cabra vacunada durante toda su vida, y por lo tanto, no es necesaria la revacunación ${ }^{(8,9)}$. Estos resultados fueron la base para el uso de la vacunación con dosis reducida de Rev 1 en la Campaña Nacional contra la Brucelosis Animal.

También era notoria la falta de información científica referente a la sensibilidad y la especificidad que tenían las pruebas diagnósticas para la brucelosis caprina. En el INIFAP se realizaron evaluaciones de las pruebas diagnósticas, y se encontró que las técnicas que eran empleadas con éxito en los bovinos, como eran el anillo en leche y el rivanol, no eran útiles para ser empleadas en el diagnóstico de la brucelosis en las cabras. Se observó que la prueba de tarjeta, que es la técnica tamiz básica y más importante para el diagnóstico serológico de la brucelosis en los animales, debería ser usada a una concentración celular del 3\% en esta especie, pues con esta modificación se aumentaba su sensibilidad; esta prueba tamiz fue reconocida para el diagnóstico de la brucelosis en caprinos con una sensibilidad del $98 \%$ y especificidad del $100 \%$ por la Norma Oficial Mexicana. La metodología para la elaboración del antígeno se transfirió a la Productora Nacional de Biológicos Veterinarios (PRONABIVE) $^{(10,11)}$. 
Es un dogma que los machos cabríos no pueden ser vacunados contra la brucelosis, porque se presentan lesiones en los órganos reproductivos por haber un tropismo de la bacteria hacia ellos. Para tratar de desmentir esta aseveración, investigadores del INIFAP y de la UNAM, realizaron un estudio con 48 cabritos de seis meses de edad procedentes de rebaños libres de brucelosis, los resultados obtenidos demostraron que ambas vacunas tienen baja capacidad de colonización en el tracto reproductor ${ }^{(12)}$.

\section{Retos y prospectivas en México}

A corto plazo, se espera que se realicen cambios y actualizaciones en la Norma Oficial Mexicana, NOM-041-ZOO-1995, denominada Campaña Nacional contra la Brucelosis Animal; a mediano plazo, se deberán realizar programas de control de la enfermedad, adecuados a las condiciones particulares que tiene la caprinocultura en nuestro país; y a largo plazo, se debe esperar que la brucelosis caprina esté controlada en nuestro país.

\section{Clamidiasis}

La clamidiasis, es una enfermedad infecto-contagiosa y zoonótica, causada por bacterias del género Chlamydia. La especie que más afecta a las cabras es $C$. abortus; bacteria intracelular obligada que presenta un ciclo de desarrollo multimórfico asincrónico ${ }^{(13)}$.

Esta enfermedad se caracteriza por provocar abortos en el último tercio de la gestación o el nacimiento de crías débiles. El aborto ocurre generalmente sin signos previos, aunque se pueden presentar entre 24 a $48 \mathrm{~h}$ previas al aborto, cambios de comportamiento y descargas vaginales que contienen un gran número de cuerpos elementales, que ocurre en las dos o tres últimas semanas de gestación ${ }^{(13)}$. Las lesiones placentarias se desarrollan inicialmente en el hilio del placentoma y se extienden hasta involucrar las membranas intercotiledonarias. Esto conduce a la destrucción del tejido placentario que afecta la adquisición de nutrientes y la regulación hormonal y resulta en la expulsión prematura del feto. Los cambios histológicos en la placenta y la aparición de lesiones ocurren típicamente después de los 90 días de gestación ${ }^{(13)}$.

La clamidiasis es una zoonosis, y se ha descrito que afecta a las mujeres embarazadas, principalmente después de la exposición con cabras infectadas ${ }^{(13)}$.

En México. En 1997 se realizó el primer reporte de aislamiento del agente etiológico en caprinos $^{(14)}$. En nuestro país la clamidiasis se consideraba exótica, sin embargo, existía cada vez más evidencia de su presencia en los rebaños caprinos; en 2015 con el objetivo de aislar a $C$. abortus en cabras lecheras de rebaños con problemas de abortos en el estado de Guanajuato, México, y desarrollar pruebas diagnósticas adecuadas para su detección, se 
tomaron muestras de suero e hisopos vaginales de seis rebaños caprinos. La prueba ELISA mostró $9.60 \%$ de animales seropositivos a C. abortus. El PCR a partir del ADN de exudado vaginal dio como resultado $23.8 \%$ de animales positivos. Se aisló Chlamydia spp. en el $26.98 \%$ de animales muestreados. Los tres métodos diagnósticos probados resultaron complementarios y de gran valor, ya que se podían aplicar en zonas donde se sospecha que Chlamydia está causando abortos. En el trabajo se demostró que este patógeno está presente en los rebaños lecheros de México ${ }^{(15)}$.

En el estado de Guanajuato en 2016, se obtuvieron 1,307 muestras serológicas de caprinos distribuidas en 14 municipios. Se analizaron mediante la técnica de ELISA indirecta, en las hembras con antecedente de aborto, se encontró una frecuencia del $46.62 \%$; en muestras de hembras con al menos un parto, clínicamente sanas y que convivían con hembras que abortaron fue del $27.13 \%{ }^{(16)}$. En un estudio realizado en Culiacán, Sinaloa, se determinó la presencia de $C$. abortus en un rebaño caprino con problemas de abortos, sumándose a los casos ya existentes en el país ${ }^{(17)}$.

\section{Aportaciones de las investigaciones realizadas en el INIFAP}

El primer aislamiento de la bacteria en cabras de México se logró en colaboración de investigadores del entonces INIP y de la UNAM ${ }^{(14)}$. Durante los años de 2012 a 2013, se obtuvieron 186 muestras procedentes de 49 rebaños de los estados de Coahuila, Jalisco, Puebla, Veracruz y Querétaro, se realizó aislamiento bacteriano, PCR y secuenciación, el análisis de la secuencia de los productos de amplificación mostró una homología del $99 \%$ con $C$. abortus cepa A.22, FAS, S26, EBA y VPG ${ }^{(18)}$. En un estudio realizado en diferentes municipios del estado de Guanajuato, se demostró la presencia de C. abortus en cabras que provenían de rebaños con problemas de abortos y que en algunos daban tratamiento con tetraciclinas para prevenirlo. Con las muestras de los órganos y exudado vaginal fue posible corroborar, que el tratamiento no evita la infección, pudiendo o no generar el aborto ${ }^{(19)}$.

\section{Retos y prospectivas en México}

Generar conocimiento de las especies de Chlamydia que afectan a los caprinos, para establecer dentro de los rebaños medidas de prevención y control, se deberán tener establecidas en los laboratorios, pruebas moleculares PCR punto final y PCR tiempo real para el correcto diagnóstico de la enfermedad ${ }^{(17,19)}$ y en cuanto al diagnóstico, es necesario encaminar los esfuerzos en el desarrollo de técnicas rutinarias, como son las pruebas serológicas como el ELISA ${ }^{(20)}$. 


\section{Colibacilosis}

La colibacilosis es una enfermedad ocasionada por Escherichia coli, una de las principales afecciones causadas por esta bacteria son las diarreas en cabritos. Se reconocen dos formas principales de la enfermedad, la colibacilosis entérica y la sistémica. La forma entérica afecta animales de dos a ocho días de edad. Se presenta un cuadro de diarrea que por lo general es de color blanco amarillento, de consistencia cremosa a casi líquida, el cabrito presenta debilidad, caquexia y deshidratación. Si los animales no son sometidos a un tratamiento adecuado y rápido, pueden morir a las $12 \mathrm{~h}$ de iniciado el cuadro clínico. La forma septicémica afecta animales de entre dos a seis semanas de edad; las bacterias atraviesan la mucosa intestinal o respiratoria y pasan al torrente circulatorio, provocando que los animales presenten aumento de la temperatura rectal, meningitis y artritis, sin presentar diarreas. Los animales infectados son la fuente de transmisión más importante, siendo la vía fecal-oral la más frecuente. La disminución de la exposición a la bacteria se obtiene a través de prácticas de higiene y de manejo. La falta de calostro ocasiona que los cabritos sean más susceptibles a sufrir diarreas ${ }^{(21)}$.

En México. Una de las dos principales causas de mortalidad en cabritos son las diarreas ${ }^{(22)}$. Los mecanismos patogénicos e identificación de genes de virulencia involucrados en diarreas por E. coli en caprinos son escasos; la mayoría de las cepas aisladas a partir de animales pertenecen al grupo de E. coli enterotoxigénicos (ETEC), los cuales expresan como factores de patogenicidad las adhesinas y las enterotoxinas, y son los responsables de los casos de enteritis neonatales. Otros patotipos que se han aislados a partir de animales enfermos son $E$. coli enteropatógena (EPEC), la cual también es causa de diarreas y E. coli enterohemorrágica (EHEC), que tiene gran importancia debido al papel que juega como agente patógeno en humanos ${ }^{(23)}$.

La infección en el humano es debida a E. coli $\mathrm{O} 157: \mathrm{H} 7$, que pertenece al patotipo EHEC, los reservorios de esta cepa son los rumiantes. La contaminación fecal del agua y de otros alimentos, así como la contaminación cruzada durante la preparación de estos (con productos cárnicos, superficies y utensilios de cocina contaminados), también es causa de infecciones ${ }^{(24)}$.

\section{Aportaciones de las investigaciones realizadas en el INIFAP}

En un estudio realizado en el año 2014 se caracterizaron aislamientos de E. coli obtenidos a partir de diarreas de cabritos de algunas regiones caprinas de México; se encontró que los aislamientos pertenecen en su mayoría al grupo filogenético B1, del serotipo O25:H8, los cuales poseen una amplia variedad de genes de virulencia, destacando los genes st y stx2 que muestran una combinación para los patotipos EHEC y ETEC, además de presentar escasa 
resistencia a los quimioterapéuticos ${ }^{(25,26)}$. Con tres de estas cepas, se elaboró una bacterina para el control de la enfermedad, la cual se aplicó a cabras gestantes, proporcionando una sólida inmunidad pasiva a los cabritos por medio del calostro, solo $2.31 \%$ de las hembras vacunadas tuvieron crías con diarrea. Así mismo se comprobó que con la aplicación de la bacterina se incrementaron los niveles de anticuerpos en hembras vacunadas y en sus crías; de acuerdo con estos resultados la protección conferida en los animales mostró ser serotipo específico contra el LPS purificado O25 ${ }^{(27)}$.

\section{Retos y prospectivas en México}

Es necesario continuar con la investigación del comportamiento de los genes de virulencia involucrados en las diarreas ocasionadas por E. coli; con el fin de realizar un diagnóstico pertinente que permita orientar y establecer medidas preventivas específicas; se debe continuar con el desarrollo de protocolos de inmunización, con la bacterina desarrollada en INIFAP para evitar la diarrea en cabritos.

\section{Complejo respiratorio infeccioso (CRIC)}

En su presentación se involucran varios factores, como son el medio ambiente, las condiciones del animal y la presencia de los agentes infecciosos como los virus y las bacterias. La población más susceptible a este padecimiento son los cabritos. Las condiciones medioambientales adversas que predisponen a los caprinos a padecer problemas respiratorios son los cambios bruscos en el clima, el hacinamiento de los animales, corrales inadecuados, falta de ventilación, acumulación de polvo y amoniaco, deficiente protección contra las corrientes de aire y estrés por transportación ${ }^{(28)}$.

Con respecto a los agentes infecciosos, se ha mencionado la participación de algunos virus como agentes primarios; siendo los más importantes el de Parainfluenza-3 y el Respiratorio Sincitial ${ }^{(29)}$. Una vez deprimidos los mecanismos de defensa, las bacterias presentes en la flora nasal o en el medio ambiente colonizan a los pulmones. Las bacterias que participan en el CRIC son Pasteurella multocida, Mannheimia haemolytica y Mycoplasma spp. Estas bacterias son comúnmente encontradas en el tracto respiratorio alto de animales sanos ${ }^{(30)}$. Los factores relacionados al huésped que pueden contribuir a la presentación del CRIC o neumonía incluyen desde un deficiente calostrado de los cabritos, un sistema mucociliar dañado por los virus, lo que hace deficiente una remoción bacteriana en los conductos aéreos, un sistema inmune deficiente, desnutrición, parasitosis, deshidratación, etc. Cuando se presenta la neumonía se manifiestan fiebres de 40 a $41^{\circ} \mathrm{C}$, tos, dificultad para respirar, falta de apetito, descarga mucopurulenta tanto nasal como ocular, depresión, postración y muerte $^{(31)}$. 
En México. Los problemas neumónicos son reconocidos por los caprinocultores como uno de los más frecuentes relacionados con la sanidad de sus rebaños, pero en pocas ocasiones se realiza diagnóstico y se establecen programas de prevención ${ }^{(22)}$.

\section{Aportaciones de las investigaciones realizadas en el INIFAP}

El INIFAP inició el abordaje de esta problemática realizando estudios de identificación, caracterización y factores de virulencia de las bacterias participantes en el CRIC, los resultados han demostrado que, P. multocida está presente en las cabras, con el biotipo D:3. Para complementar el estudio sería interesante aislar a los microorganismos de lesiones directamente del pulmón de los individuos enfermos para confirmar que son los causantes de una neumonía ${ }^{(32-35)}$.

\section{Retos y prospectivas en México}

Se pretende formular un toxoide de $M$. haemolytica de aislamientos nacionales que, aunada a nuestra bacterina, se evalue en cabritos, con la finalidad de ser utilizada, en los calendarios de vacunación para prevenir el CRIC. También es importante realizar cursos de capacitación dirigido a los caprinocultores para que realicen una prevención adecuada del CRIC, ya que se debe de enfocar de forma integral, revisando y corrigiendo los factores ya mencionados, como son las prácticas de manejo que provoquen demasiado estrés, establecer medidas de higiene, revisar el estado nutricional, determinar el estado de parasitosis, corregir las instalaciones para proteger a los animales de los cambios bruscos de temperatura y las corrientes de aire, además de proporcionarles la ventilación correcta.

\section{Fiebre Q}

La fiebre Q es una enfermedad causada por la bacteria Coxiella burnetii, de distribución mundial y con características de zoonosis. Tiene como hospederos especies animales domesticas: vacas, ovejas, cabras, perros, gatos, conejos; y especies silvestres: pequeños roedores, zorros. La mayoría de estos animales son portadores crónicos y no sufren la enfermedad, pero excretan bacterias a través de orina, heces, leche y productos del parto como líquido amniótico, placenta y abortos. Estas secreciones forman aerosoles que transmiten al microorganismo por vía aérea a la población susceptible ${ }^{(36)}$.

En México Al tener carácter exótico en nuestro país, desde 1994 es considerada por la SADER como una enfermedad de notificación obligatoria ${ }^{(37)}$. En 1990 se reportó en Baja California la primera evidencia serológica en animales ${ }^{(38)}$. Los primeros reportes en humanos de C. burnetii son de la Comarca Lagunera ${ }^{(39)}$. 


\section{Aportaciones de las investigaciones realizadas en el INIFAP}

En un estudio realizado de 2018 a 2019, por investigadores del INIFAP y del Sector Salud, con el objetivo de evidenciar la presencia de $C$. burnetii en caprinos que presentaron aborto, se identificó mediante PCR punto final la secuencia de inserción IS1111. Estos datos son la primera evidencia molecular de que los caprinos de nuestro país pueden ser reservorios de C. burnetii ${ }^{(40)}$.

\section{Retos y prospectivas en México}

A corto plazo, se espera que se cambie el estado de la enfermedad de exótica a endémica, para continuar con investigación en el desarrollo de pruebas de diagnóstico; a mediano plazo se deberán tener establecidas en los laboratorios, pruebas diagnósticas de elevada sensibilidad y especificidad para la detección de la enfermedad tanto en animales como en humanos, así como realizar programas de control para la Fiebre Q en los animales.

\section{Lentivirus de pequeños rumiantes}

El virus de la artritis encefalitis caprina (vAEC) y virus Maedi-visna, presentan similitudes genéticas, estructurales y patogénicas, por lo que han sido reclasificados como lentivirus de los pequeños rumiantes $(\mathrm{LvPR})^{(41)}$. La importancia económica para la industria caprina se relaciona directamente con la presencia de infecciones crónicas-degenerativas multisistémicas e incurables. En cabras adultas se observa artritis y mastitis, mientras que en cabritos, la presentación es nerviosa y se presenta durante los primeros meses de edad ${ }^{(42)}$. La replicación de los lentivirus en células epiteliales de la glándula mamaria juega un papel importante en la transmisión de partículas virales; las células mononucleares y macrófagos infectados también pueden eliminarse a través del calostro y leche. El contacto directo con secreciones respiratorias, aerosoles, orina, y heces provenientes de animales infectados, son consideradas fuentes de infección que toman mayor relevancia durante el hacinamiento. El agua y alimento, así como una inadecuada desinfección de instalaciones, maquinaria y material de ordeño, permite la propagación de los $\mathrm{LvPR}^{(43)}$.

En México. En el año de 1985, se realizó un estudio de seroprevalencia del vAEC en regiones productoras de caprinos; se determinó que la enfermedad ingresó a través de la importación de animales de pie de cría procedentes de los Estados Unidos de América ${ }^{(44)}$. Posteriormente, la SAGARPA, incluyó a la AEC, como enfermedad endémica de reporte obligatorio mensual. El vAEC fue aislado y se realizó la secuenciación del genoma completo de un LvPR recombinante perteneciente al subtipo $\mathrm{B} 1^{(45)}$. 


\section{Aportaciones de las investigaciones realizadas en el INIFAP}

En el INIFAP, se están desarrollado técnicas de diagnóstico, acordes a las características genéticas y antigénicas de cepas que circulan de forma natural en el país y que afectan la producción caprina. Se ha logrado la expresión de un antígeno recombinante de la proteína p25 del virus de la AEC, en el sistema de E. coli; se considera que los antígenos generados son excelentes candidatos para el establecimiento de una prueba serológica de tipo ELISA que contribuya al diagnóstico de la $\mathrm{AEC}^{(46)}$. Se está estandarizando una prueba de $\mathrm{PCR}$ en tiempo real que identifique la presencia de provirus y en la producción de proteínas recombinantes CA, p25 y MA, p16 del lentivirus.

\section{Retos y prospectivas en México}

Se pretende generar conocimiento sobre la circulación de otros grupos genéticos de LvPR y determinar la diversidad genética que existe en el país; la evidencia científica indica hasta el momento, la presencia del genogrupo B1, que es capaz de infectar tanto a ovinos como caprinos. Con base en esta información, se han desarrollado herramientas y técnicas para el diagnóstico serológico y molecular del subtipo B1 (ELISA y PCR). Si bien en el mundo no se ha desarrollado alguna prueba serológica o molecular capaz de detectar todos los grupos o subtipos de LvPR existentes, la estrategia que ha dado mejores resultados es la de caracterizar la diversidad y con la información obtenida, complementar o adecuar las pruebas desarrolladas para atender las necesidades actuales o futuras en cada país, recomendar a los productores de pie de cría y ganado de registro su participación en programas oficiales para la certificación de rebaño libre de LvPR y poder beneficiar a otros productores de menor recurso económico mediante programas sociales de apoyo gubernamental. A largo plazo, se pretende que las principales regiones productoras de caprinos estén certificadas como libres, así como establecer una cultura de sanidad animal basada en el diagnóstico oportuno que permita incrementar la productividad.

\section{Leptospirosis}

La leptospirosis es una enfermedad infecciosa ocasionada por bacterias pertenecientes al género Leptospira, tiene una amplia distribución en todo el mundo, tanto en zonas rurales como urbanas, que cuentan con características climatológicas y orográficas particulares, redes pluviales naturales, extensas áreas agrícolas y presencia de lluvias estacionales que favorecen la propagación de Leptospira spp., afectando en diferentes formas que van desde la infección asintomática, aguda o crónica, a mamíferos domésticos y silvestres. Este microorganismo se elimina por la orina de los animales infectados de forma continua o intermitente, contaminando así al medio ambiente. La leptospirosis en cabras en su forma aguda pude presentar aumento de temperatura, anorexia, depresión, ictericia, y anemia; sin 
embargo, en su forma crónica provoca abortos, momificaciones, infertilidad, nacimientos prematuros y mortalidad neonatal, lo que ocasiona importantes pérdidas económicas ${ }^{(47)}$. En el humano, al ser un hospedero ocasional de este microorganismo, le puede provocar distintos trastornos patológicos como fiebre, cefalea, dolores musculares y articulares, tos, derrame, náuseas, vómito, ictericia y afecciones de riñón e hígado ${ }^{(48)}$.

En México. En un estudio en el estado de Veracruz, se analizaron 873 muestras de suero; las serovariedades más frecuentes fueron Wolffi $(45.58 \%)$ e Icterohaemorragiae $(45.13 \%)^{(49)}$. En la Comarca lagunera se obtuvieron 802 muestras de suero, de las cuales el $60.1 \%$ resultaron seropositivos a leptospirosis ${ }^{(50)}$. En rebaños caprinos del estado de Guerrero, se encontró que $64.26 \%$ de las muestras presentaron títulos de anticuerpos contra al menos una de las serovariedades de Leptospira interrogans ${ }^{(51)}$.

\section{Aportaciones de las investigaciones realizadas en el INIFAP}

En el año 2016 investigadores del INIFAP, determinaron la frecuencia serológica de anticuerpos contra Leptospira spp en las principales zonas caprinas del estado de Guanajuato, reportando una frecuencia de leptospirosis del $37.90 \%{ }^{(52)}$.

En 2018 se determinó la seroprevalencia de serovariedades de Leptospira spp., en caprinos del Estado de Guanajuato y se evaluaron los patrones de distribución geográfica y coexposición. Se analizaron 1,640 muestras mediante la prueba de aglutinación microscópica. Se obtuvo una prevalencia total de $45.5 \%$; la prevalencia de Icterohaemorrhagiae fue $34.16 \%$, seguida de Hardjo con $6.77 \%$; el resto de serovariedades diagnosticadas fue menor a $5 \%$, todas ellas mostraron un patrón de agregación que pueden sugerir zonas de riesgo y vectores que transmiten la enfermedad; el análisis de la coocurrencia de anticuerpos, revela el comportamiento dominante de Icterohaemorrhagiae, sobre el resto de las serovariedades diagnosticadas ${ }^{(53)}$. En 2019 se realizó el diagnóstico serológico de las principales enfermedades abortivas en cabras del estado de Guanajuato. Los muestreos se realizaron en granjas lecheras, con diferentes niveles de tecnificación, razas y manejo. Se confirmó la presencia de seropositividad a Leptospira spp $^{(54)}$.

\section{Retos y prospectivas en México}

Implementar medidas de prevención y control en los rebaños, a través de la inmunización con serovariedades de Leptospira spp. previamente diagnosticadas en caprinos, con la finalidad de disminuir los problemas de abortos, momificaciones, partos prematuros e infertilidad ocasionados por la enfermedad. 


\section{Linfadenitis caseosa}

La linfadenitis caseosa es una enfermedad infecciosa de curso crónico que afecta a caprinos; es causada por Corynebacterium pseudotuberculosis, patógeno intracelular facultativo capaz de replicarse y sobrevivir en el interior de fagocitos. Se caracteriza por la presencia de lesiones supurativas en los linfonodos, pulmones y otros órganos viscerales. La presentación subclínica de la enfermedad es la visceral, los abscesos se localizan en órganos internos como pulmón, hígado y linfonodos mesentéricos; en ocasiones, los animales presentan cuadros de neumonía crónica y adelgazamiento progresivo ${ }^{(55)}$.

\section{Aportaciones de las investigaciones del INIFAP}

El INIFAP ha contribuido en el desarrollo de pruebas de diagnóstico, así como en la caracterización genética de las cepas de origen ovino, caprino y equino ${ }^{(56)}$. En otra investigación realizada en el INIFAP, se logró el establecimiento de una prueba de reacción en cadena de la polimerasa múltiple para el diagnóstico de linfadenitis caseosa en caprinos, demostrando que, es una técnica eficiente a partir de muestras clínicas; este protocolo diagnóstico también tiene la capacidad de diferenciar entre cepas de C. pseudotuberculosis de los biovares ovis y equi ${ }^{(57)}$.

Otro grupo de investigadores del INIFAP se ha dado a la tarea de iniciar el estudio de cepas mutantes como candidatos para el desarrollo de inmunógenos. Sin embargo, la cepa mutante no logró proteger a los ratones Balb/c después del desafío experimental, y no demostró una adecuada respuesta inmune humoral y celular en el modelo murino ${ }^{(58)}$.

\section{Retos y prospectivas en México}

Los trabajos realizados en el INIFAP permitirán a corto o mediano plazo contar con un biológico capaz de reducir la morbilidad y el impacto económico y productivo de esta enfermedad en México.

\section{Paratuberculosis}

La paratuberculosis es causada por la bacteria Mycobacterium avium subespecie paratuberculosis. Esta infección se caracteriza por generar una inflamación crónica regional en el intestino delgado de los rumiantes. Los signos más frecuentes en la paratuberculosis en cabras son la disminución en la condición corporal y del peso, así como la baja en la producción láctea, la pérdida de consistencia de las heces y los cuadros diarreicos que solo se manifiestan durante la fase terminal de la enfermedad ${ }^{(59)}$. 
M. avium subsp. paratuberculosis ha sido asociada en múltiples ocasiones con la enfermedad de Crohn, un padecimiento crónico que causa inflamación y ulceración del tracto gastrointestinal, principalmente en la porción del íleon y colon ${ }^{(60)}$, sin embargo, no es reconocido como el agente etiológico principal.

En México. La primera evidencia de la enfermedad en cabras fue reportada en 1983; en dicho reporte se logró constatar el cuadro clínico de la enfermedad, el hallazgo de lesiones intestinales como la enteritis y granulomas en ganglios linfáticos mesentéricos, la presencia de la bacteria en los tejidos lesionados, así como anticuerpos en el suero sanguíneo de los animales estudiados ${ }^{(61)}$. A partir de estos trabajos, han surgido diversos reportes sobre la seroprevalencia, el aislamiento y la detección del material genético de la bacteria en animales infectados en varios estados de la República Mexicana ${ }^{(59,61,62)}$.

\section{Aportaciones de las investigaciones realizadas en el INIFAP}

Aunque las prevalencias de la enfermedad en caprinos son variables, se ha logrado establecer cuáles son los factores de riesgo en la transmisión de la enfermedad entre los rebaños nacionales. Dentro de ellos se pueden mencionar la elevada densidad poblacional, el ingreso de animales infectados a los rebaños, la permanente convivencia con otras especies, la permanencia de animales infectados y finalmente, las malas condiciones de higiene ${ }^{(63)}$.

\section{Retos y prospectivas en México}

El reto a corto plazo es idear estrategias que permitan diferenciar el cuadro clínico asociado a la baja condición corporal y la disminución de la producción láctea provocada por la infección, de otras condicionantes comunes en la mayoría de los rebaños de México, como son la mal nutrición por carencia de alimentos de buena calidad, sobre todo en zonas donde es común el pastoreo comunitario. El reto a mediano plazo es dar seguimiento a los rebaños de las zonas de producción caprina más importantes de México para evaluar el impacto sanitario, productivo y económico que tiene la enfermedad en la producción caprina nacional. A largo plazo, disminuir sustancialmente la prevalencia e incidencia de la enfermedad, garantizando la inocuidad en los alimentos, el aumento en la productividad y la apertura a nuevos canales de comercialización, ya que en países como los Estados Unidos de América y la comunidad europea, los animales libres de esta enfermedad y sus subproductos tienen mayor valor económico y comercial.

\section{Literatura citada:}

1. Servicio de Información Agroalimentaria y Pesquera [SIAP]. Inventario 2019 caprino. www.gob.mx.SIAP. 
2. Escareño L, Wurzinger M, Pastor F, Salinas H, Sölkner J, Iñiguez L. The goat and goat production systems of small-scale producers of the Comarca Lagunera in Northern Mexico. Rev Chapingo Ser Cs Forest Amb 2011;12:235-246.

3. SAGARPA. Anuario Estadístico de la Producción Agropecuaria. Región Lagunera Durango-Coahuila. Secretaria de Agricultura, Ganadería, Desarrollo Rural, Pesca y Alimentación. México. 2007.

4. Barrera POT, Sagarnaga VLM, Salas GJM, Leos RJA, Santos LR. Viabilidad económica y financiera de la ganadería caprina extensiva en San Luis Potosí, México. Mundo Agrario 2018;19:40.

5. Blasco JM. Control and eradication strategies for Brucella melitensis infection in sheep and goats. Prilozi 2010;31(1):145-165.

6. Lebre A, Velez J, Seixas D, Rabado E, Oliveira J, Saraiva da Cunha J, Silvestre AM. Brucellar spondylodiscitis: case series of the last 25 years. Acta Med Port 2014;27(2):204-210.

7. Díaz-Aparicio E, Marín C, Alonso B, Aragón V, Pardo M, Blasco JM, Díaz R, Moriyón I. Evaluation of serological tests for diagnosis of Brucella melitensis infection of goats. J Clin Microbiol 1994;32:1159-1165.

8. Mancera A, Díaz AE, Vázquez NJ, Velázquez F, Suárez GF, Flores CR. Vacunación de cabras con la cepa Rev 1 de Brucella. melitensis en diferentes dosis: Evaluación serológica y desafío. Vet Méx 1992;2:117-123.

9. Díaz-Aparicio E, Hernández AL, Suárez-Güemes F. Protection against brucellosis in goats, five years after of vaccination with Brucella melitensis Rev 1 vaccine in reduce dose. Trop Anim Health Prod 2004;36:117-121.

10. Díaz AE, Blasco MJM, Suárez GF. Prueba de tarjeta modificada para el diagnóstico de la brucelosis caprina. Vet Méx1999;30(4):307-311.

11. Díaz-Aparicio E, Marin C, Alonso-Urmeneta B, Aragón V, Pérez-Ortiz S et al. Evaluation of serological tests for diagnosis of Brucella melitensis infection of goats. $\mathrm{J}$ Clin Microbiol 1994;32:1159-1165.

12. López VIA. Efecto del eritritol en la colonización de Brucella melitensis (Rev1 eryCD), en el tracto reproductor de machos cabríos [tesis maestría]. CDMX: Universidad Nacional Autónoma de México; 2020.

13. Essig A, Longbottom D. Chlamydia abortus: New aspects of infectious abortion in sheep and potential risk for pregnant women. Curr Clin Micro 2015; Rpt 2;22-34. 
14. Escalante-Ochoa C, Diaz-Aparicio E, Segundo-Zaragoza C, Suarez-Guemes F. Isolation of Chlamydia psittaci involved in abortion of goats in Mexico: first report. Rev Latinoam Microbiol 1997;39:117-121.

15. Mora-Díaz J, Díaz-Aparicio E, Herrera-López E, Suárez-Güemez F, Escalante-Ochoa C, Jaimes-Villareal S, Arellano-Reynoso B. Isolation of Chlamdia abortus; in dairy goat herds and its relation to abortion in Guanajuato, Mexico. Veterinaria México OA 2015;2(1).

16. García LX. Frecuencia de clamidiosis en casos de cabras que presentaron aborto en el estado de Guanajuato [tesis maestría] CDMX: Universidad Nacional Autónoma de México; 2019.

17. Romero JA. Diagnóstico de Chlamydia abortus, mediante cultivo celular y PCR de un rebaño caprino con problemas de abortos en Culiacán, Sinaloa [tesina licenciatura] CDMX: Universidad Autónoma Metropolitana; 2020.

18. Sánchez RL. Presencia de Chlamydia abortus en cabras de México [tesis maestría] México, DF: Universidad Nacional Autónoma de México; 2014.

19. Hernández RP. Presencia de genes de resistencia $(\operatorname{tet}(\mathrm{C})$-tetR(C)) a tetraciclina en aislamientos de Chlamydia abortus [tesis maestría] CDMX: Universidad Nacional Autónoma de México; 2020.

20. Santiago BC. Expresion de OmpA recombinante deChlamydia abortus en Escherichia coli [tesis maestría] CDMX: Universidad Nacional Autónoma de México; 2019.

21. García De Jalón CJA. Diarreas en corderos y cabritos. PR 2000;1(1):8-14.

22. Cuellar OJA, Tortora PJ, Trejo GA, Román RP. La producción caprina mexicana, particularidades y complejidades. 1era ed. UNAM, México: Aridana; 2012.

23. Matthew AC, Robyn JL. Recent advances in understanding enteric pathogenic Escherichia coli. Clin Microbiol 2013;26(4):822-880.

24. Organización Mundial de la Salud [OMS]. E. coli. 2018.

25. Martínez FRI. Identificación de genes de virulencia en aislados de E. coli de origen caprino [tesis maestría] DF: Universidad Nacional Autónoma de México; 2014.

26. Yáñez VA. Determinación de factores de virulencia y clonalidad de cepas de E. coli procedentes de diarrea de cabritos [tesis maestría] DF: Universidad Nacional Autónoma de México; 2016. 
27. Limón GMM. Desarrollo y evaluación en campo de una bacterina de E. coli, en caprinos [tesis maestría] México: Universidad Nacional Autónoma de México; 2017.

28. Rahal A, Ahmad AH, Prakash A, Mandil R, Kumar AT. Environmental attributes to respiratory diseases of small ruminants. Vet Med Int 2014;10.

29. Lamontagne L, Descoteaux JP, Roy R. Epizootiological survey of Parainfluenza-3, Reovirus-3, Respiratory Syncytial and Infectious Bovine Rhinotracheitis Viral antibodies in sheep and goat flocks in Quebec. Can J Comp Med 1985;49:424-428.

30. Ponnusamy P, Masilamoni BS, Ranjith KM, Manickam R. Isolation, identification and antibiogram of Mannheimia hemolytica associated with caprine pneumonia in the Cauvery Delta Region of Tamil Nadu, India. Int J Curr Microbiol Appl Sci 2017;6(9): 3118-3122.

31. Blanco VFJ, Trigo TFJ, Jaramillo ML, Aguilar RF, Tapia PG, Suárez GF. Serotipos de Pasteurella multocida y Pasteurella haemolytca aislados a partir de pulmones con lesiones inflamatorias en ovinos y caprinos. Vet Mex 1993;24(2):107-112.

32. Pérez-Romero N, Aguilar-Romero F, Arellano-Reynoso B. Isolation of Histophilus somni from the nasal exudates of a clinically healthy adult goat. Trop Anim Health Prod 2011;43:901-903.

33. Soriano VE, Vega SV, Zamora EJL, Aguilar RF, Negrete AE. Identification of Pasteurella multocida capsular types isolated from rabbits and other domestic animals in Mexico with respiratory diseases.Trop Anim Health Prod 2012;44, 935-937.

34. Martínez RI. Aislamiento, identificación y caracterización de Mannheimia haemolytica y Pasteurella multocida aisladas de caprinos [tesis maestría] México DF: Universidad Nacional Autónoma de México; 2013.

35. Rojas-Fernández M, Vaca S, Reyes-López M, de la Garza M, Aguilar-Romero F, Zenteno E, Soriano VE, Negrete-Abascal E. Outer membrane vesicles of Pasteurella multocida contain virulence factors. Microbiologyopen 2014;3(5):711-717.

36. Hartzell JD, Wood-Morris RN, Martinez LJ, Trotta RF. Q fever: epidemiology, diagnosis, and treatment. Clinic Proc 2008;83(5):574-579.

37. ACUERDO mediante el que se da a conocer en los Estados Unidos Mexicanos las enfermedades y plagas exóticas y endémicas de notificación obligatoria de los animales terrestres y acuáticos. DOF publicado el 29/11/2018.

38. Salman MD, Hernández JA, Braun Y. A seroepidemiological study of five bovine diseases in dairy farms of the coastal region of Baja California, Mexico. Prev Vet Med 1990;9(2):143-153. 
39. Silva R. Fiebre Q en México. Méd Rev Méx 1950;61(7):493-497.

40. Flores PCF. Identificación de Coxiella burnetii, bacteria exótica en México, mediante PCR, en caprinos y bovinos que presentaron aborto [tesis maestría] CDMX Universidad Nacional Autónoma de México; 2020.

41. Gómez-Lucia E, Barquero N, Domenech A. Maedi-Visna virus: current perspectives. Vet Med 2018;9:11-21.

42. Straub OC. Maedi-Visna virus infection in sheep. History and present knowledge. Comp Immunol Microbiol Infect Dis 2004;27(1):1-5.

43. Blacklaws BA, Berriatua E, Torsteinsdottir S, Watt NJ, de Andres D, Klein D, Harkiss GD. Transmission of small ruminant lentiviruses. Vet Microbiol 2004;101(3):199-208.

44. Nazara SJ, Trigo FJ, Suberbie E, Madrigal V. Estudio serológico de la artritisencefalitis caprina en México. Tec Pecu Mex 1985;48:96-101.

45. Ramírez H, Glaria I, de Andrés X, Martínez HA, Hernández MM, Reina R, et al. Recombinant small ruminant lentivirus subtype B1 in goats and sheep of imported breeds in Mexico. J Vet 2011;190(1):169-172.

46. Valladares RB. Generación y caracterización de la proteína p25 del Lentivirus de pequeños rumiantes (LvPR), expresada en Escherichia coli [tesis maestría] México: Universidad Nacional Autónoma de México; 2016.

47. Suwancharoen D, Chaisakdanugull Y, Thanapongtharm W, Yoshida S. Serological survey of leptospirosis in livestock in Thailand. Epidemiol Infect 2013;141(11).

48. Gamage CD, Koizumi N, Perera AK, Muto M, Nwafor-Okoli C, Ranasinghe S, et al. Carrier status of leptospirosis among cattle in Sri Lanka: a zoonotic threat to public health. Transbound Emerg Dis 2014;61(1):91-96.

49. Fernández TAI, Herrera LE, Díaz AE, Barradas PF, Cristóbal CO, Limón GMM. Leptospirosis caprina en diferentes municipios del estado de Veracruz. Congreso Nacional de Buiatria. Acapulco, Guerrero. 2013:694-697.

50. García GN. Estudio Epidemiológico de Leptospirosis Caprina en la Región Lagunera del Estado de Coahuila [tesis licenciatura]. Torreón, Coahuila: Universidad Autónoma Agraria “Antonio Narro", 2011.

51. López HA. Diagnóstico serológico de Leptospira spp y de C. abortus en las principales zonas de producción caprina del estado de Guerrero, México. [tesis licenciatura] México, DF: Universidad Nacional Autónoma de México; 2011. 
52. Flores PP. Diagnóstico serológico de Leptospira interrogans y Brucella melitensis en rebaños caprinos en el estado de Guanajuato [tesis licenciatura] CDMX: Universidad Nacional Autónoma de México; 2016.

53. Gaytán CF. Seroprevalencia, distribución geográfica y co-exposición de serovariedades de Leptospira spp. en rebaños caprinos pertenecientes a grupos ganaderos de validación y transferencia de tecnología del estado de Guanajuato [tesis licenciatura] CDMX: Universidad Nacional Autónoma de México; 2018.

54. Rueda GY. Seroprevalencia de enfermedades abortivas en cabras de unidades de producción pertenecientes a la región centro-oriente de Guanajuato [tesis especialidad] Querétaro: Universidad Autónoma de Querétaro; 2019.

55. Windsor PA. Control of caseosus lyphadenitis. Vet Clin Food Anim 2011;27:193-202.

56. Parise D, Parise MTD, Viana MVC, Muñoz-Bucio AV, Cortés-Pérez YA, ArellanoReynoso B, et al. First genome sequencing and comparative analyses of Corynebacterium pseudotuberculosis strains from Mexico. Standards in Genomic Sci 2018;13:21.

57. Quiroga VDB. Evaluación de una técnica de reacción en cadena de la polimerasa para diagnóstico de linfadenitis caseosa de los pequeños rumiantes. [tesis licenciatura] Cuautitlán Universidad Nacional Autónoma de México; 2019.

58. Ibarra ZC, Arellano RB, Hernández CR, Palomares REG, Díaz AE. Evaluation of the aroA mutant of Corynebacterium pseudotuberculosis in cellular and murine models. Vet Méx 2016;3:4:1-16.

59. Velázquez MJ, et al. Detection of Mycobacterium avium subsp. Paratuberculosis in reproductive tissue and semen of naturally infected rams. Animal Rep 2019;(4):930937.

60. Yamamoto FJK. Crohn's disease: diagnosis and treatment. Rev Gastroenterol Mex 2013;78(Supl 1): 68-70.

61. Ramírez PC, Ramírez CIC, Valero EG, Trigo TE. Paratuberculosis en cabras en México. Tec Pecu Mex 1983;45:104-106.

62. Gallaga MEP, Arellano RB, Santillán FMA, Favila HLC, Córdova LD, Morales JR, Díaz AE, Situación epidemiológica de la paratuberculosis en las principales regiones caprinas del estado de Puebla, México. Quehacer Científico en Chiapas 2017;12(1).

63. Ruiz CCG, Flores MAS, López DC. Prevalence and possible risk factors for caprine paratuberculosis in intensive dairy production units in Guanajuato, Mexico. J Vet Med Anim Health 2016;8(11):156-162. 